\title{
Understanding technology acceptance in pre-service teachers of primary mathematics in Hong Kong
}

\author{
Gary K. W. Wong
}

The Hong Kong Institute of Education

\begin{abstract}
The adoption of educational technology in teaching depends on how well a teacher accepts it. This paper draws on a technology acceptance survey of pre-service primary mathematics teachers in Hong Kong to study the factors influencing their technology acceptance. This work adopted a mixed method approach, in which quantitative data were collected through questionnaire survey from 234 pre-service teachers, where the data were analysed using structural equation modelling with a customised technology acceptance model. The qualitative data were also collected from 14 of these pre-service teachers through interviews, and analysed using the iterative coding process. The results show an overall positive attitude towards the use of educational technology, while perceived usefulness is more influential than perceived ease of use. Perceived ease of use is found to rely heavily on facilitating conditions rather than computer self-efficacy. We also found that subjective norms have an indirect influence on the usage and adoption in our context. Explanations for these findings are discussed, together with implications of the results. Our findings are intended to provide insights to policy makers about how to design teacher education programmes that address the demands of learning and teaching with educational technologies in Hong Kong and related contexts.
\end{abstract}

\section{Introduction}

The advancement of information and communications technologies (ICTs) in the past decade has had a great impact on education. Research shows that ICTs can potentially benefit teaching and learning if used appropriately (Fadel \& Lemke, 2009; Roschelle, Pea, \& Hoadley, 2000; Schacter, 1999). Mathematics education, in particular, benefits from ICT through visualisation and active knowledge construction involving abstract concepts and higher order thinking (Wenglinsky, 1998). In addition, Mishra and Koehler (2006) propose the Technological Pedagogical Content Knowledge (TPCK) to integrate content, pedagogy, and technology, so that technology can be appropriately incorporated into teaching and the potential benefits of this integration realised. This suggests that the implementation of ICT in teaching and learning requires pedagogical knowledge in addition to other knowledge and skills.

Most importantly, technologies need to be accepted by teachers or students in the first place before considering training them to use technologies for various purposes (e.g. teaching and learning). However, research shows that this acceptance is not trivial. A recent study by Kennedy and Fox (2013) report that Hong Kong students use ICT as a tool only for looking up information and storing it. Few students were aware of the Web 2.0 features that could facilitate active learning. Another study by Dutton, Cheong, and Park (2004) in the United States showed that students typically underutilise the potential of the course management system. This phenomenon is also observed among teachers. West, Waddoups, and Graham (2006) report limited and selective adoption of ICTs among in-service teachers, who regard educational technologies as unnecessary, time-consuming, inflexible, and difficult to use. From a cost control perspective, this phenomenon fails to justify the educational expenditure spent on these technologies. From an educational perspective, the lack of technology uptake suggests that many opportunities for enhancing education through the use of newly available tools are lost.

Promoting a more comprehensive use of educational technologies by both teachers and students requires knowledge of the factors contributing to their acceptance. Future teachers, who are currently undertaking full-time undergraduate pre-service education programmes, deserve special attention. Attitude is generally one important factor of technology acceptance. Understanding their attitudes towards technology may help pre-service teacher education programmes to more effectively promote the use of technology for their current learning. At the same time, these learning experiences may further promote their use of technologies in the future. Other factors may also contribute to the technology acceptance, which is essential to promoting learning in technology-enriched environment. 
This study aims to investigate the factors influencing technology acceptance in the future teaching of a group of undergraduate pre-service teachers in Hong Kong, majoring in primary mathematics education. It adopts a mixed method approach in which quantitative data are collected through questionnaire survey and qualitative data through interviews. A rich body of empirical research has focused on technology acceptance among diverse groups of users in various settings (see e.g., Legris, Ingham, and Collerette [2003], for a review of earlier papers; or Kirmizi [2014], Lee, Hsieh, and Chen [2013], Mac Callum and Jeffrey [2014], and Sieche, Krey, and Bastiaens [2013] as examples of more recent works). However, relatively few studies have targeted pre-service teachers (Hayes \& Ohrnberger, 2013; Irvine \& Birch, 2009; Teo, Luan, \& Sing, 2008). To the best of our knowledge, only one study (Yuen \& Ma, 2002) has investigated pre-service teachers in Hong Kong and their acceptance of technology in their future teaching once qualified (rather than considering their current learning as students). The participants in Yuen and Ma's (2002) study were degree holders pursuing a 1 year postgraduate certificate in education, which differs from the focus of this paper. The results of the present study are expected to benefit policy makers and school administrators who want to promote the use of technologies by undergraduate pre-service teachers in their current learning and future teaching.

\section{Literature review}

\section{Technology acceptance vs. technology adoption}

It is necessary to distinguish between the terms adoption and acceptance. Straub (2009) states that an adoption theory "examines the individual and the choices an individual makes to accept or reject a particular innovation” (p.626), indicating that he regards these as different, though related concepts. Renaud and van Biljon (2008) make this more explicit by defining technology adoption as a process in which a person first becomes aware of the technology, then embraces it and finally makes full use of it. In contrast, technology acceptance is an attitude towards technology influenced by various factors. This paper focuses on the technology acceptance of pre-service teachers, defined as the successful development of their behavioural intention to use the technology in their future teaching. It should be noted however that behavioural intention is only one factor of actual use. Use falls outside of the scope of this paper since it could not be measured at the present time.

\section{Theoretical models of technology acceptance}

There are various theoretical models used in technology acceptance research (see, e.g., Straub [2009] and Venkatesh, Morris, Davis, and Davis [2003] for comprehensive reviews). A popular candidate among these is the technology acceptance model (TAM) (Davis, 1985). Building on the Theory of Reasoned Action (Ajzen \& Fishbein, 1977) and the Theory of Planned Behaviour (Ajzen, 1991), TAM postulates that the behavioural intention (BI) to use a technology depends on the potential user's attitude towards the technology, which in turns depends on the perceived usefulness and perceived ease of use. Attitude (ATT) refers to an individual's personal affection towards the technology (that is, whether it is a good idea, interesting, and fun). Perceived usefulness (PU) is the perception of how useful the technology may be in terms of the increase in productivity and accomplishment that it will bring. Perceived ease of use (PEU) refers to whether or not the technology is clear and understandable from the individual's perspective when learning or using the technology. Figure 1 shows a diagram of the TAM.

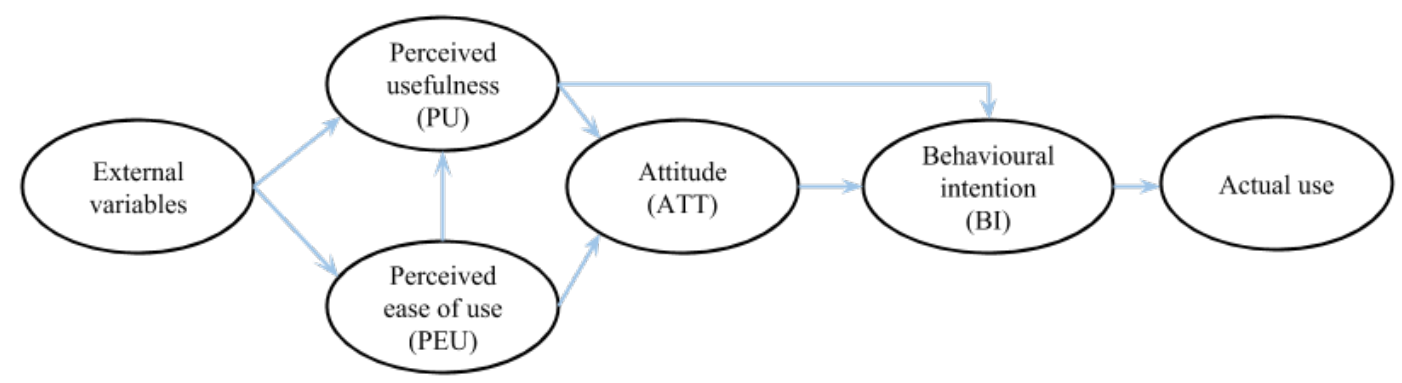

Figure 1. Technology acceptance model (TAM) (Davis, 1985) 
External variables have also been cited as indirect factors affecting behavioural intention. Common ones include computer self-efficacy (EFF), subjective norms (SN), and facilitating conditions (FC). Computer self-efficacy is the person's perception of how well he/she can handle the difficulties in using and learning about the technology. This is not the same as perceived ease of use: A person may find an aspect of technology difficult to use, but may still have the confidence to tackle the difficulty. Subjective norm is measured by how strongly a person thinks that others want him/her to use educational technology. Facilitating conditions refer to the perception of availability of resources, knowledge, and technical support that could assist or facilitate the use of the technology.

\section{Empirical studies of technology acceptance of pre-service teachers}

Empirical literature on technology acceptance has identified some universal patterns across many studies. However, many differences can be found if these results are inspected in more detail. For example, Legris et al. (2003) surveyed 22 TAM studies (covering 28 measurements) and showed that the PU-ATT, PU-BI, and PEU-PU relations are supported in over $80 \%$ of the models tested, but these relations vary considerably in strength across studies, giving rise to very different conclusions.

As far as pre-service teachers are concerned, Teo and colleagues are among the small number of researchers who have studied technology acceptance among pre-service teachers around the world. For example, Teo, Luan, and Sing (2008) surveyed 250 and 245 pre-service teachers from Singapore and Malaysia respectively. They found that while both samples showed a significant relation between PU-ATT, PU-BI, and PEU-PU, the relation of ATT-BI was very strong in the Malaysian sample while it did not reach statistical significance in the Singaporean group. A later study surveying 475 pre-service teachers in Singapore, that included facilitating conditions, technology complexity, and computer self-efficacy as external variables, found consistent results for PU-ATT, PU-BI, and PEU-PU. Attitude and computer selfefficacy were also found to have direct effects on intention, the latter of which had the strongest effect (Teo, 2009). Data from a Turkish sample of 297 pre-service teachers indicated that perceived usefulness was a key determinant of behavioural intention, followed by computer self-efficacy, that also had direct but weaker effects (Teo \& Ursavas, 2012).

A few other authors have conducted similar studies. Yuen and Ma (2002) explored the technology acceptance of 186 pre-service teachers in Hong Kong. They found that perceived usefulness was the only factor leading directly to behavioural intention of use, while perceived ease of use only acted through perceived usefulness. Their participants were degree holders rather than undergraduate students. They also used a simple model that did not include any external variables in contrast to the models developed by later researchers. Their results therefore provided limited use for our context.

Aypay, Celik, Aypay, and Sever (2012) studied the technology acceptance of 754 pre-service teachers in Turkey and found that perceived usefulness and attitude towards computer use were the only two direct factors affecting behavioural intention of use, while all other factors only had indirect effects. Another study, also using Turkish data, surveyed 320 pre-service teachers in Turkey and supported the PU-BI relation (Kiraz \& Ozdemir, 2006). Similar results for PU-BI were found in a study of 84 pre-service teachers in Sweden (Ma, Andersson, \& Streith, 2005). An exception is Irvine and Birch (2009), who found that perceived ease of use was the only predictor of behavioural intention, using data from 85 pre-service teachers in Canada. Although finding out the major cause to these differences is beyond our scope, it is generally true that the technology adoption process can differ from different cultures and populations (Schepers \& Wetzels, 2007; Straub, Keil, \& Brenner, 1997). Thus, the phenomena observed from other cultures or populations in existing literatures may or may not be applicable to our local context, and the study in our own culture is necessary to find out the factors of adoption.

\section{Research model and hypotheses}

This study aims to investigate the factors contributing to Hong Kong pre-service teachers' behavioural intentions (BI) to use technology in their future teaching. The model used in this study adheres to the original structure proposed by Davis (1985). Computer self-efficacy (EFF), subjective norms (SN), and facilitating conditions (FC) were chosen as the external variables acting on perceived usefulness (PU) and perceived ease of use (PEU) because these are commonly used and also appear in newer models such as 
UTAUT (Venkatesh et al., 2003). An extra link is added to relate computer self-efficacy and behavioural intention following Teo (2009).

Taking these into consideration, our research model is constructed as shown in Figure 2. The 12 hypotheses to be tested are listed below for clarity:

- H1: ATT has a direct effect on BI

- H2: PU has a direct effect on BI

- H3: PU has a direct effect on ATT

- H4: PEU has a direct effect on PU

- H5: PEU has a direct effect on ATT

- H6: EFF has a direct effect on PU

- H7: EFF has a direct effect on PEU

- H8: EFF has a direct effect on BI

- H9: FC has a direct effect on PU

- H10: FC has a direct effect on PEU

- H11: SN has a direct effect on PU

- H12: SN has a direct effect on PEU

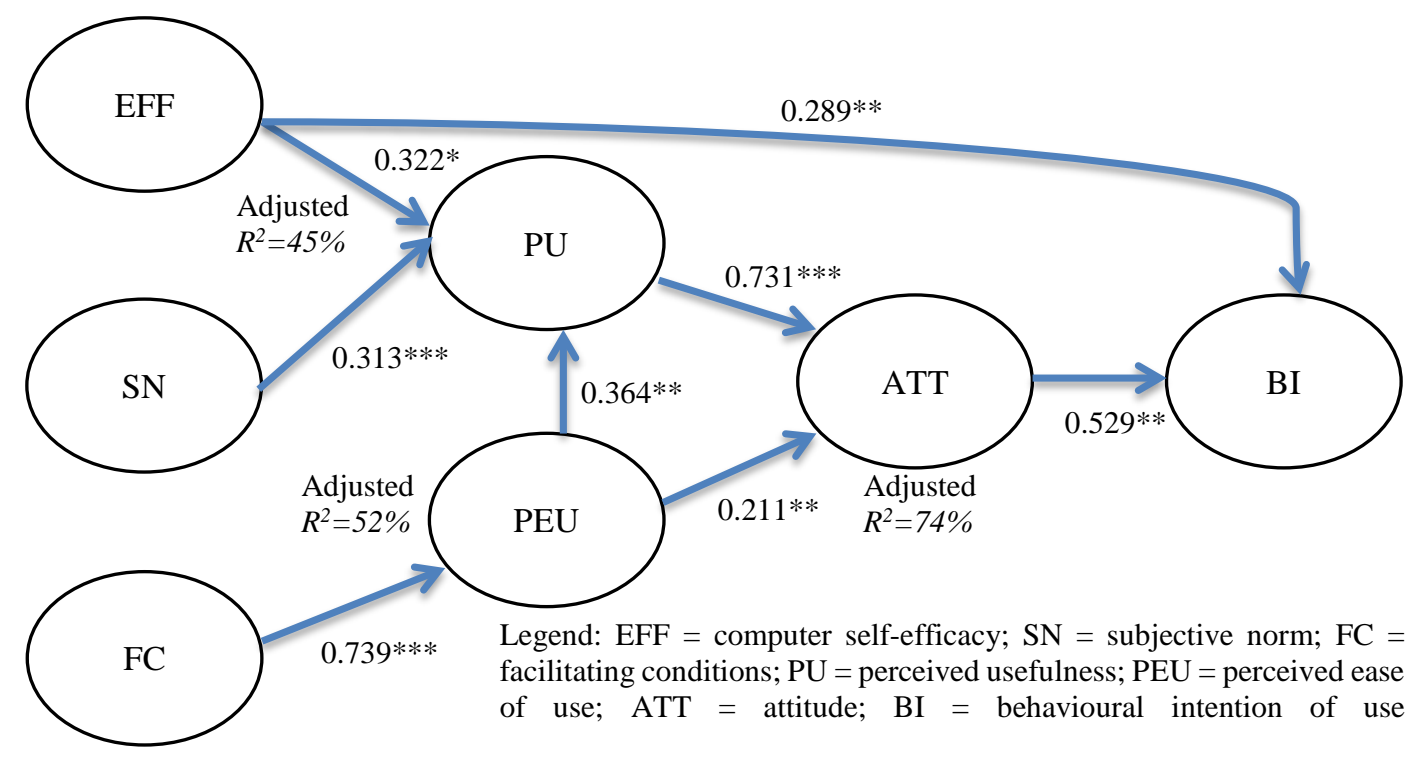

Figure 2. Theoretical model used in our study

\section{Methodology}

\section{Context and population}

This study surveyed the entire population of undergraduate students registered in the Bachelor of Education (Honours) (Primary Mathematics) programme at the authors' institution. Students in this programme are in their first, second, third or fourth year of study, and are hereafter referred to as Year 1, Year 2, Year 3, and Year 4 students respectively. The estimated population size is 370. These pre-service teachers are expected to start their teaching careers in local primary schools teaching mathematics and related disciplines. They come from a similar age group and subject discipline, but their experience with technologies may vary.

\section{Instrument for quantitative data collection}

Quantitative data were collected via a questionnaire. The questionnaire asked the participants for their views about using technology in their future teaching, in situations where they are free to make these decisions. Although Davis' (1985) TAM model is used, the questionnaire items, shown in Table 1, are 
adapted from the equivalent constructs of later work by Venkatesh et al. (2003). The original English version was used to avoid translation-related errors, however wording was modified so that it was appropriate for the current context in line with common practices of other researchers (e.g., Marques, Villate, \& Carvalho, 2011), and items were renumbered. Answers were collected on a 5-point Likert scale. The questionnaire asked for students' gender, age, and experience in using technology in teaching and learning. Students were asked to leave their contact details if they were willing to participate in a followup interview.

Table 1

List of constructs and items (adapted from Venkatesh et al. [2003] and renumbered)

\begin{tabular}{|c|c|c|}
\hline Construct & Code & Item \\
\hline \multirow{4}{*}{$\begin{array}{l}\text { Perceived usefulness } \\
\text { (PU) }\end{array}$} & PU1 & I would find educational technology useful in my teaching. \\
\hline & PU2 & $\begin{array}{l}\text { Using educational technology enables me to accomplish teaching } \\
\text { tasks more quickly. }\end{array}$ \\
\hline & PU3 & $\begin{array}{l}\text { Using educational technology increases my productivity (i.e. } \\
\text { accomplishes more with less effort and time). }\end{array}$ \\
\hline & PU4 & $\begin{array}{l}\text { Using educational technology will increase my chances of getting a } \\
\text { promotion. }\end{array}$ \\
\hline \multirow[t]{4}{*}{$\begin{array}{l}\text { Perceived ease of use } \\
\text { (PEU) }\end{array}$} & PEU1 & $\begin{array}{l}\text { My interaction with educational technology would be clear and } \\
\text { understandable. }\end{array}$ \\
\hline & PEU2 & $\begin{array}{l}\text { It would be easy for me to become skilful at using educational } \\
\text { technology. }\end{array}$ \\
\hline & PEU3 & I would find educational technology easy to use. \\
\hline & PEU4 & Learning to use educational technology is easy for me. \\
\hline \multirow[t]{4}{*}{ Attitude (ATT) } & ATT1 & Using educational technology is a good idea. \\
\hline & ATT2 & Educational technology makes my work more interesting. \\
\hline & АТТ3 & Educational technology is fun. \\
\hline & ATT4 & I like using educational technology in teaching. \\
\hline \multirow[t]{3}{*}{ Subjective norm (SN) } & SN1 & $\begin{array}{l}\text { I believe that people who influence my behaviour will think that I } \\
\text { should use educational technology. }\end{array}$ \\
\hline & SN2 & $\begin{array}{l}\text { I believe that people who are important to me will think that I } \\
\text { should use educational technology. }\end{array}$ \\
\hline & SN3 & $\begin{array}{l}\text { I believe that the school will support the use of educational } \\
\text { technology. }\end{array}$ \\
\hline \multirow[t]{3}{*}{$\begin{array}{l}\text { Facilitating conditions } \\
\text { (FC) }\end{array}$} & FC1 & $\begin{array}{l}\text { I believe that I will have the resources necessary to use educational } \\
\text { technology. }\end{array}$ \\
\hline & FC2 & I have the knowledge necessary to use educational technology. \\
\hline & FC3 & $\begin{array}{l}\text { I believe that a specific person or group (e.g. technical support } \\
\text { team) will be available for assistance with difficulties using } \\
\text { educational technology. }\end{array}$ \\
\hline \multirow{5}{*}{$\begin{array}{l}\text { Computer self-efficacy } \\
\text { (EFF) }\end{array}$} & & I could complete a job or task using educational technology... \\
\hline & EFF1 & ... even if there was no one around to tell me what to do as I go. \\
\hline & EFF2 & ... if I could call someone for help if I got stuck. \\
\hline & EFF3 & ... if I had enough time. \\
\hline & EFF4 & ... if I had access to the instruction manuals for the technology. \\
\hline \multirow{3}{*}{$\begin{array}{l}\text { Behavioural intention } \\
\text { of use (BI) }\end{array}$} & BI1 & I intend to use educational technology in my future teaching. \\
\hline & $\mathrm{BI} 2$ & I predict I would use educational technology in my future teaching. \\
\hline & $\mathrm{BI3}$ & $\begin{array}{l}\text { I have an actual plan to use educational technology in my future } \\
\text { teaching. }\end{array}$ \\
\hline
\end{tabular}




\section{Quantitative data collection, manipulation, and analysis}

The questionnaire data was collected in two rounds. In the first round, the instructor or student helpers delivered the questionnaires to students during class in paper form. They were requested to fill in the questionnaire and return it to the researcher immediately on completion. Participation was entirely voluntary and the students were not required to write their names unless they agreed to take part in future follow-up interviews. In addition an electronic questionnaire (with online or PDF printable option) was prepared for Year 4 students, who were on practicum and could not be reached in class. The second round of data collection was conducted in a similar way except that the data were collected from another cohort of students entering Year 1 in the following academic year. These students are regarded as Year 1 students in the demographics due to the same admission criteria to the programme studies.

Data from the completed questionnaires were entered into the computer for preliminary data manipulation. Any record with missing data was discarded. Outliers and unusual responses were also noted. After removal of these records, a confirmatory factor analysis (CFA) was conducted to identify any questionnaire items with small factor loadings using the measurement model. These items were then removed from further analysis. The data were then reanalysed, this time using structural equation modelling (SEM) with the complete measurement and structural model described in Figure 2.

While a quantitative approach can inform us about the generalisable relations between constructs, it is not comprehensive in explaining the reasons behind these relations. It is restricted by the hypotheses of the theoretical model at the outset. This study therefore adopts a mixed method approach in which follow-up interviews are used to collect additional qualitative data to triangulate with the quantitative results, as described immediately below.

\section{Follow-up qualitative interviews}

Follow-up individual interviews were conducted after the questionnaire survey. The students were invited if and only if they indicated their voluntariness in the questionnaire. All the interview sessions were conducted in one of the authors' office, and the sessions were conducted in the presence of the two authors. No other persons except for the one interviewee and the two interviewers were present in the room, while all interviewees were assured of the confidentiality of their identity in data reporting. Each session lasted for about half an hour. The interviews were semi-structured. They were guided by the following generic questions:

1. What are your learning experiences with computers in this institution?

2. Do you find educational technologies useful to your learning and your future teaching? Why or why not?

3. Do you find educational technologies easy to use in your experience? Why or why not?

4. Will you use educational technologies in your future teaching? If yes, why and how? If no, why not?

The first question aims to seek for factual description of the interviewees' experience with technology in general in their study. The second and third questions specifically ask about the interviewees' comments on the usefulness and ease of use of the educational technologies based on such learning experience, as well as the reasons behind them. The last question asks about the overall attitude and behavioural intention for the interviewees to adopt educational technology in their future teaching. These questions together collect qualitative data that could be triangulated with the quantitative model, as well as to provide additional insights on the reasons behind the choices of the interviewees.

In operation, the interviewers began each session by asking the interviewee to casually talk about their experiences using technology for learning and teaching at the institution. They then asked the interviewees to further elaborate some of the points they made about the use of technology in their practicum or future teaching, using the above questions as guidelines. The interviewees were nevertheless allowed to talk freely on whatever they thought were relevant.

The interviews were conducted in Cantonese, Mandarin, or English depending on the native language or personal choice of the interviewees. All sessions were audio-recorded and transcribed in their original 
language. The scripts were then analysed using the iterative coding process in Creswell (2002) to identify the categories, themes, and patterns that emerged from the data. Specifically, the transcript of the interview session was read through once to identify the main ideas. Then, it was re-read in more detail and the ideas were labelled with codes. The codes were developed on the fly but all the interview transcripts shared the same set of codes. This process was repeated three to four times for each interview transcript to reduce overlap and redundancy of the codes, until a relatively small set of sub-themes (categorised under a few major themes) were identified. To facilitate the triangulation with the quantitative data, the major themes were chosen so as to align with the constructs used in the TAM in the study.

Due to convenience sampling, the authors make no attempt to generalise the qualitative findings to the whole sample of the questionnaire survey or to the whole population of students. The interviews aimed to collect qualitative data to triangulate with the quantitative data as well as to seek for further insights on the reasons behind the quantitative relations between the constructs. A synthesis of the qualitative data is given in a subsequent section after the quantitative findings.

\section{Results}

\section{Demographic statistics of quantitative data}

A total of 253 questionnaires were returned in the two rounds of quantitative data collection. One student responded with "5" to all questions and that questionnaire was discarded. A further 18 questionnaires contained missing data. Removal of these 19 questionnaires left 234 valid responses, with 166 cases coming from the first round and 68 cases coming from the second round. The use of SEM requires a relatively large sample size (Lei \& Wu, 2007), although what constitutes large varies from author to author. Hair, Anderson, Tatham, and Black (1995) recommend a sample size of 100 to 200 for maximum likelihood estimation (MLE), which is close to what we are using. A sample size bigger than 400 is considered too large and would cause the goodness-of-fit measures to be too sensitive such that they detect any difference between the model and the data. Some other authors have suggested larger sample sizes of 200 or more (Boomsma, 1983; Lei \& Wu, 2007). Our sample size fits well within the suggested range of the literature reviewed. Of the 234 students who participated in the study, 19 indicated that they were willing to attend a follow-up interview.

Table 2 shows the demographic statistics of the student participants. The participants are fairly homogeneous in age; all of them except two were born in the 1980s or later, an age group referred to by Prensky (2001) as native speakers of the digital language of computers, video games, and the Internet. In terms of gender, $69.7 \%$ of the respondents are female. This matches roughly with the overall student distribution in the institution. 
Table 2

Demographic statistics of quantitative data

\begin{tabular}{|c|c|c|}
\hline Items & Frequency & Percentage \\
\hline \multicolumn{3}{|l|}{ Gender } \\
\hline Female & 163 & 69.7 \\
\hline Male & 71 & 30.3 \\
\hline Total & 234 & 100.0 \\
\hline \multicolumn{3}{|l|}{ Year of Birth } \\
\hline 1970 or before & 1 & 0.4 \\
\hline 1971-1980 & 1 & 0.4 \\
\hline 1980-1990 & 21 & 9.0 \\
\hline After 1990 & 211 & 90.2 \\
\hline Total & 234 & 100.0 \\
\hline \multicolumn{3}{|l|}{ Year of Study } \\
\hline 1 & 114 & 48.7 \\
\hline 2 & 93 & 39.7 \\
\hline 3 & 14 & 6.0 \\
\hline 4 (online questionnaire) & 13 & 5.6 \\
\hline Total & 234 & 100.0 \\
\hline \multicolumn{3}{|c|}{$\begin{array}{l}\text { Enrolled in relevant courses at } \\
\text { the institute before? }\end{array}$} \\
\hline Yes & 24 & 10.3 \\
\hline No & 209 & 89.3 \\
\hline Did not answer & 1 & 0.4 \\
\hline Total & 234 & 100.0 \\
\hline \multicolumn{3}{|c|}{$\begin{array}{l}\text { Experience with educational } \\
\text { technologies }\end{array}$} \\
\hline $\begin{array}{l}\text { Never learned about it } \\
\text { formally }\end{array}$ & 104 & 44.4 \\
\hline Learned, but not used & 78 & 33.3 \\
\hline $\begin{array}{l}\text { Learned, and used for at } \\
\text { least one semester }\end{array}$ & 52 & 22.2 \\
\hline Total & 234 & 100.0 \\
\hline
\end{tabular}

\section{Descriptive statistics}

The descriptive statistics for the constructs are given in Table 3. The possible range of scores is from 1.00 to 5.00, with the mid-point of the range at 3.00. From the table it can be seen that all the mean scores are above this mid-point. The skewness and kurtosis are also included. Kline (2005) suggests that the absolute values of the skewness and kurtosis of the data should be bounded under 3 and 10 respectively to satisfy the univariate normality requirement of MLE. Our figures fall within the suggested ranges. On the other hand, multivariate normality is difficult to assess, but multivariate non-normality is "detectable through inspection of univariate distributions" and can be removed by deletion of outliers (p.49). The distributions of the answers were inspected one by one for this purpose. Except for the already discarded questionnaire with all " 5 " in the answers, no outliers were found in our data.

Table 3 shows that attitude has a relatively high mean score of 3.84, showing that this sample of students has a positive attitude (ATT) towards educational technology in general. Similarly, the score of 3.78 for perceived usefulness (PU) shows that the students, in general, think that educational technology is useful. 
Table 3

Descriptive statistics of the constructs

\begin{tabular}{lllll}
\hline Construct & Mean & $\begin{array}{l}\text { Standard } \\
\text { Deviation }\end{array}$ & Skewness & Kurtosis \\
\hline Perceived usefulness (PU) & 3.78 & 0.59 & -0.55 & 1.57 \\
Perceived ease of use (PEU) & 3.61 & 0.74 & -0.41 & -0.19 \\
Attitude (ATT) & 3.84 & 0.66 & -0.52 & 0.88 \\
Subjective norm (SN) & 3.58 & 0.61 & -0.11 & 0.15 \\
Facilitating conditions (FC) & 3.67 & 0.59 & -0.12 & -0.19 \\
Computer self-efficacy (EFF) & 3.70 & 0.59 & -0.47 & 1.56 \\
Behavioural intention of use (BI) & 3.61 & 0.67 & -0.55 & 0.94 \\
\hline
\end{tabular}

\section{Factor analysis}

The data were first analysed using a CFA without the structural model to detect possible issues with the questionnaire. Many authors use a recommended lower bound of 0.50 for AVE, while the recommended lower bounds for factor loading, Cronbach's alpha, and composite reliability are 0.70 (see, e.g. Nistor, Lerche, Weinberger, Ceobanu, \& Heymann, 2014). However, as with the recommended sample size, there are different guidelines suggested by different authors. For example, some authors point out that a factor loading as low as 0.45 would be adequate if the sample size is larger than 150 , or 0.50 if the sample size is larger than 120 (Hair et al., 1995).

Two rounds of CFA were conducted in our analysis. The first round considered the measurement model only to preliminarily identify any item with low factor loadings. It turned out that three of the factor loadings were marginal at 0.468 (PEU1), 0.360 (SN3) and 0.450 (FC3) indicating that the responses to these questions might be inconsistent with other answers tapping the same construct. One possible reason is that the students may not fully understand the questions presented to them in their second language, or that the students interpreted the questions in a different way to how they were actually intended. This may indicate a need to translate the questionnaires and conduct the survey in the native language of the participants. Moreover, some questions in FC and EFF may not be appropriate as they required students to consider their future working environment. To resolve this issue, the three items were removed, following the practice of some other studies (Göğüş, Nistor, \& Lerche, 2012; Nistor, Lerche, Weinberger, Ceobanu, \& Heymann, 2014). The whole set of data was then re-analysed, this time with the complete SEM. The result of this second round of factor analysis is given in Table 4 for a convergent validity check. In this table, the factor loadings are given for each item. The average variance extracted (AVE), Cronbach's alpha, and composite reliability are given for each construct. 
Table 4

Factor analysis and convergent validity

\begin{tabular}{|c|c|c|c|c|c|}
\hline Constructs & Item & Factor loading & AVE & $\begin{array}{l}\text { Cronbach's } \\
\text { alpha }\end{array}$ & $\begin{array}{l}\text { Composite } \\
\text { Reliability } \\
\text { (Omega) }\end{array}$ \\
\hline \multirow{4}{*}{$\begin{array}{l}\text { Perceived } \\
\text { usefulness } \\
\text { (PU) }\end{array}$} & PU1 & 0.679 & \multirow[t]{4}{*}{0.45} & \multirow[t]{4}{*}{0.750} & \multirow[t]{4}{*}{0.757} \\
\hline & PU2 & 0.756 & & & \\
\hline & PU3 & 0.669 & & & \\
\hline & PU4 & 0.547 & & & \\
\hline \multirow{4}{*}{$\begin{array}{l}\text { Perceived ease } \\
\text { of use (PEU) }\end{array}$} & PEU1 & Eliminated & \multirow[t]{4}{*}{0.65} & \multirow[t]{4}{*}{0.844} & \multirow[t]{4}{*}{0.851} \\
\hline & PEU2 & 0.743 & & & \\
\hline & PEU3 & 0.821 & & & \\
\hline & PEU4 & 0.852 & & & \\
\hline \multirow{4}{*}{$\begin{array}{l}\text { Attitude } \\
\text { (ATT) }\end{array}$} & ATT1 & 0.662 & \multirow[t]{4}{*}{0.49} & \multirow[t]{4}{*}{0.798} & \multirow[t]{4}{*}{0.797} \\
\hline & ATT2 & 0.677 & & & \\
\hline & ATT3 & 0.712 & & & \\
\hline & ATT4 & 0.759 & & & \\
\hline \multirow{3}{*}{$\begin{array}{l}\text { Subjective } \\
\text { norm (SN) }\end{array}$} & SN1 & 0.771 & \multirow[t]{3}{*}{0.62} & \multirow[t]{3}{*}{0.758} & \multirow[t]{3}{*}{0.76} \\
\hline & SN2 & 0.798 & & & \\
\hline & SN3 & Eliminated & & & \\
\hline \multirow{7}{*}{$\begin{array}{l}\text { Facilitating } \\
\text { conditions } \\
\text { (FC) } \\
\text { Computer self- } \\
\text { efficacy (EFF) }\end{array}$} & FC1 & 0.580 & \multirow[t]{3}{*}{0.47} & \multirow[t]{3}{*}{0.621} & \multirow[t]{3}{*}{0.621} \\
\hline & FC2 & 0.777 & & & \\
\hline & FC3 & Eliminated & & & \\
\hline & EFF1 & 0.571 & \multirow[t]{4}{*}{0.38} & \multirow[t]{4}{*}{0.693} & \multirow[t]{4}{*}{0.693} \\
\hline & EFF2 & 0.564 & & & \\
\hline & EFF3 & 0.682 & & & \\
\hline & EFF4 & 0.630 & & & \\
\hline \multirow{3}{*}{$\begin{array}{l}\text { Behavioural } \\
\text { intention (BI) }\end{array}$} & BI1 & 0.833 & \multirow[t]{3}{*}{0.56} & \multirow[t]{3}{*}{0.765} & \multirow[t]{3}{*}{0.765} \\
\hline & $\mathrm{BI} 2$ & 0.817 & & & \\
\hline & $\mathrm{BI3}$ & 0.565 & & & \\
\hline
\end{tabular}

To check the discriminant validity, the lower triangular correlation matrix of the composite scores of the constructs is presented with its diagonal elements replaced by the square root of the AVE for each construct. The result is shown in Table 5. The fact that the diagonal elements are larger than all the off-diagonal elements in its own row and column indicates that the constructs correlate more with their own items than with other constructs. Discriminant validity is thus verified in our process.

Table 5

Discriminant validity (correlation matrix with diagonal elements replaced by square root of AVE)

\begin{tabular}{llllllll}
\hline & PU & PEU & ATT & SN & FC & EFF & BI \\
PEU & $\mathbf{0 . 6 7}$ & & & & & & \\
ATT & 0.50 & $\mathbf{0 . 8 1}$ & & & & & \\
SN & 0.64 & 0.55 & $\mathbf{0 . 7 0}$ & & & & \\
FC & 0.41 & 0.30 & 0.34 & $\mathbf{0 . 7 8}$ & & & \\
EFF & 0.39 & 0.51 & 0.43 & 0.39 & $\mathbf{0 . 6 9}$ & & \\
BI & 0.39 & 0.45 & 0.40 & 0.30 & 0.52 & $\mathbf{0 . 6 1}$ & $\mathbf{0 . 7 5}$ \\
\hline
\end{tabular}

\section{Fitness of model}

Table 6 displays the goodness-of-fit indices for our model compared to the recommended criteria for a good fit. The absolute fit indices measure how well the model fits the empirical data. Parsimony indices similarly examine the fit with empirical data but penalise the more complex models. Finally, the incremental fit indices compare the model with a baseline model in which the variables are assumed to be uncorrelated. 
Table 6

Goodness-of-fit measurements

\begin{tabular}{lll}
\hline Fit indices & Criteria & Value \\
\hline Absolute fit indices; & & 356.116 \\
$\chi^{2}$ (chi-squared) & - & 194 \\
$d f$ (degree of freedom) & - & 0.000 \\
$p$ value (chi-squared) & $<2 \quad$ (Tabachnick \& Fidell, 2012) & 1.836 \\
$\chi^{2} / d f$ & $<3 \quad$ (Kline, 2005) & \\
& $<0.08$ (Hu \& Bentler, 1999) & 0.058 \\
SRMR (standardised root mean & & \\
square residual) & & 0.060 \\
\hline Parsimony indices: & $<0.06$ (Hu \& Bentler, 1999) & \\
RMSEA (root mean square error & $<0.07$ (Steiger, 2007) & 0.919 \\
of approximation) & $>0.95$ (Hu \& Bentler, 1999) & \\
\hline Incremental fit indices: & $>0.90$ (Klem, 2000) & 0.904 \\
Comparative Fit Index & $>0.95$ (Hu \& Bentler, 1999) & \\
Tucker-Lewis Index & $>0.90$ (Klem, 2000) & \\
&
\end{tabular}

It should be noted that the use of these indices is controversial and different authors have suggested different criteria for good fit. It is common practice to report multiple indices in publication (Lei \& Wu, 2007), but some authors are more critical and reject the use of indices altogether owing to their limitations (Barrett, 2007). While it is beyond the scope of this paper to explore this issue, we follow the common practice of reporting the values of some of these indices for reference. Multiple criteria for the same index, if listed, are sorted in descending order of stringency. Nevertheless, the goodness-of-fit measurement indices show that the model may require improvement in further studies. For example, a $p$ value larger than 0.05 is desirable for the chi-squared test in this case in order not to reject the model. The Comparative Fit Index and Tucker-Lewis Index do not satisfy some of the more stringent criteria.

\section{Results of hypothesis testing}

The results of hypothesis testing are summarised in Table 7. Of the 12 hypotheses, 8 are statistically supported (defined as $p<0.05$ ). The standardised coefficients and the corresponding adjusted $R^{2}$ values are presented with the model in Figure 3. Note that the statistically insignificant links are omitted for clarity.

Table 7

\begin{tabular}{|c|c|c|c|c|c|}
\hline Hypothesis & Path & $\begin{array}{l}\text { Non- } \\
\text { standardised } \\
\text { coefficients }\end{array}$ & $\begin{array}{l}\text { Standardised } \\
\text { coefficients }\end{array}$ & $p$ value & $\begin{array}{l}\text { Results } \\
\text { (Supported if } p<0.05 \text { ) }\end{array}$ \\
\hline H1 & $\mathrm{ATT} \rightarrow \mathrm{BI}$ & $0.637 * *$ & $0.529 * *$ & 0.002 & Supported \\
\hline H2 & $\mathrm{PU} \rightarrow \mathrm{BI}$ & 0.116 & 0.079 & 0.639 & Not supported \\
\hline H3 & $\mathrm{PU} \rightarrow \mathrm{ATT}$ & $0.888 * * *$ & $0.731^{* * *}$ & 0.000 & Supported \\
\hline $\mathrm{H} 4$ & $\mathrm{PEU} \rightarrow \mathrm{PU}$ & $0.237 * *$ & $0.364^{* *}$ & 0.005 & Supported \\
\hline H5 & $\mathrm{PEU} \rightarrow \mathrm{ATT}$ & $0.166^{* *}$ & $0.211^{* *}$ & 0.005 & Supported \\
\hline H6 & $\mathrm{EFF} \rightarrow \mathrm{PU}$ & $0.274^{*}$ & $0.322 *$ & 0.023 & Supported \\
\hline H7 & $\mathrm{EFF} \rightarrow \mathrm{PEU}$ & -0.077 & -0.059 & 0.708 & Not supported \\
\hline H8 & $\mathrm{EFF} \rightarrow \mathrm{BI}$ & $0.359 * *$ & $0.289 * *$ & 0.001 & Supported \\
\hline H9 & $\mathrm{FC} \rightarrow \mathrm{PU}$ & -0.123 & -0.124 & 0.535 & Not supported \\
\hline H10 & $\mathrm{FC} \rightarrow \mathrm{PEU}$ & $1.132^{* * *}$ & $0.739 * * *$ & 0.000 & Supported \\
\hline H11 & $\mathrm{SN} \rightarrow \mathrm{PU}$ & $0.238 * * *$ & $0.313^{* * *}$ & 0.000 & Supported \\
\hline H12 & $\mathrm{SN} \rightarrow \mathrm{PEU}$ & 0.056 & 0.048 & 0.583 & Not supported \\
\hline
\end{tabular}




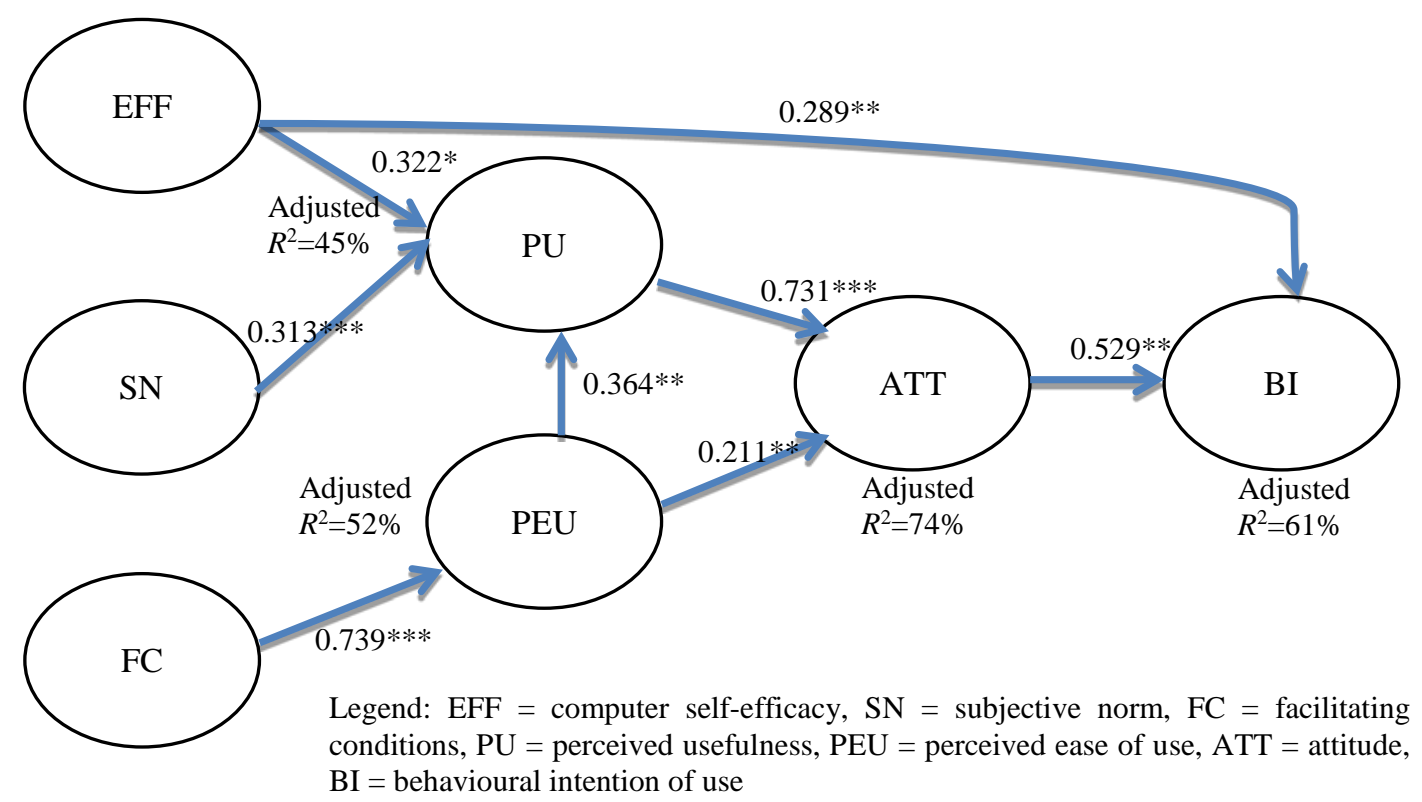

Figure 3. Theoretical model with standardised path coefficients and adjusted $R^{2}$ values

It is also useful to list the standardised direct, indirect, and total effects between the constructs (see Table 8). The standardised direct effect of one construct (A) on another (B) is equal to the standardised path coefficient from A to B. The standardised indirect effect involves calculating the effects of all the possible indirect paths between A and B. Path coefficients for the paths in a series are multiplied together, while those for the paths in parallel are added up. The total effect is the sum of the direct and indirect effect between the two constructs. Note that a link is included in the calculation even if the path coefficient is not shown to be statistically significant.

Table 8

Direct, indirect, and total effects ( $p<0.001$ : $\left.^{* * *} ; p<0.01:^{* *} ; p<0.05: *\right)$

\begin{tabular}{ll|l|lll|l}
\hline Outcome & Determinant & Adj $R^{2}$ & Direct & Indirect & Total & $\begin{array}{l}p \text { value for total } \\
\text { effect }\end{array}$ \\
\hline BI & PU & 0.61 & 0.079 & 0.387 & $0.466^{* * *}$ & 0.000 \\
& PEU & & & 0.281 & $0.281^{* * *}$ & 0.000 \\
& ATT & & 0.529 & & $0.529^{* * *}$ & 0.002 \\
& SN & & 0.160 & $0.160^{* * *}$ & 0.002 \\
& EFF & & 0.289 & 0.134 & $0.422^{* * *}$ & 0.000 \\
ATT & FC & & 0.150 & 0.150 & 0.069 \\
& PU & \multirow{4}{*}{0.74} & 0.731 & & $0.731^{* * *}$ & 0.000 \\
& PEU & & 0.211 & 0.267 & $0.477^{* * *}$ & 0.000 \\
& SN & & & 0.252 & $0.252^{* *}$ & 0.001 \\
& EFF & & & 0.207 & 0.207 & 0.073 \\
& FC & & & 0.262 & $0.262^{*}$ & 0.043 \\
& PEU & 0.45 & 0.364 & & $0.364^{* *}$ & 0.005 \\
& SN & & 0.313 & 0.017 & $0.331^{* * *}$ & 0.000 \\
& EFE & & 0.322 & -0.021 & $0.300^{*}$ & 0.032 \\
& FC & & -0.124 & 0.269 & 0.146 & 0.322 \\
& SN & 0.52 & 0.048 & & 0.048 & 0.583 \\
& EFF & & -0.059 & & -0.059 & 0.708 \\
& FC & & 0.739 & & $0.739^{* * *}$ & 0.000 \\
\hline
\end{tabular}




\section{Synthesis of qualitative results}

A total of 19 students, who were assigned sequence numbers of 1 - 19, were invited for the follow-up interviews, while eventually 14 showed up. The interviewees come from all four years of students. The demographic statistics of the interviewees is given in Table 9.

Table 9

\begin{tabular}{ccccc}
$\begin{array}{c}\text { Profiles of interviewees } \\
\begin{array}{c}\text { Sequence } \\
\text { number }\end{array}\end{array}$ & Gender & Year of study & $\begin{array}{c}\text { Attended any course } \\
\text { on educational } \\
\text { technology before? }\end{array}$ & Attended practicum? \\
\hline 1 & M & 1 & No & No \\
2 & M & 1 & No & No \\
5 & M & 4 & Yes & Yes \\
6 & F & 4 & Yes & Yes \\
7 & F & 4 & Yes & Yes \\
8 & F & 1 & No & No \\
9 & F & 2 & No & No \\
10 & F & 2 & Yes & Yes \\
11 & M & 3 & No & No \\
12 & M & 1 & Yes & Yes \\
13 & M & 4 & No & No \\
15 & F & 1 & No & No \\
16 & F & 1 & Yes & Yes \\
19 & F & 4 & & \\
\hline
\end{tabular}

To triangulate with the quantitative findings, selected excerpts are translated to English (wherever necessary) and tabulated in Table 10. To minimise the possibility of translational errors in the presentation, both authors have separately checked the translated excerpts. Each excerpt is marked with a [\#n] in the end where $n$ is the sequence number of the corresponding interviewee. The frequency of occurrence of each sub-theme is also given. This frequency may or may not be a good indication of the importance of the subtheme (Cohen, Manion, \& Morrison, 2011), but the same sub-theme being mentioned by a number of interviewees indicate that the sub-theme may be common concern shared among them. Descriptions of the results are given in the paragraphs that follow.

Table 10

Selected excerpts from the follow-up interviews

\begin{tabular}{|c|c|c|}
\hline Theme & Sub-theme & Examples \\
\hline \multirow[t]{3}{*}{$\begin{array}{l}\text { Perceived } \\
\text { usefulness }\end{array}$} & $\begin{array}{l}\text { Usefulness is } \\
\text { important } \\
\text { (mentioned by } 11 \\
\text { interviewees) }\end{array}$ & $\begin{array}{l}\text { (a) "I will use (a piece of technology) if I find it effective and } \\
\text { helpful.” [\#01] } \\
\text { (b) "Of course usefulness is more important (than ease of use). } \\
\text { Otherwise what is the point of learning it?” [\#06] } \\
\text { (c) "If it is very useful...but even it will take time to learn, I } \\
\text { think I will still give it a try.” [\#11] } \\
\text { (d) "If it is useful, I will try it out even though it is difficult to } \\
\text { use.” [\#15] }\end{array}$ \\
\hline & $\begin{array}{l}\text { Usefulness is } \\
\text { considered in terms } \\
\text { of teaching } \\
\text { effectiveness } \\
\text { (mentioned by } 2 \\
\text { interviewees) }\end{array}$ & $\begin{array}{l}\text { (e) "I think successful teaching comes from the students' } \\
\text { reactions (to my teaching), whether they can learn it well or } \\
\text { not, it does not depend on what methods I use (even with } \\
\text { technology)." [\#07] } \\
\text { (f) "I will try (the technology tools) and see how well the } \\
\text { students can accept (to my teaching). From there I make the } \\
\text { decision (to adopt the tools)" [\#12] }\end{array}$ \\
\hline & $\begin{array}{l}\text { Usefulness is } \\
\text { determined relative } \\
\text { to traditional } \\
\text { approach (non- }\end{array}$ & $\begin{array}{l}\text { (g) "If I try the teaching methods with technology and find it } \\
\text { not satisfactory, then I will go back to the traditional } \\
\text { approach (e.g. using chalk and board). If the students }\end{array}$ \\
\hline
\end{tabular}




\begin{tabular}{|c|c|c|c|}
\hline & $\begin{array}{l}\text { computer mediated } \\
\text { approach) } \\
\text { (mentioned by } 9 \\
\text { interviewees) }\end{array}$ & (h) & $\begin{array}{l}\text { respond well to my teaching, then I will continue using the } \\
\text { approach (with technology).” [\#02] } \\
\text { "If the traditional approach is good enough, I will stick to } \\
\text { the traditional approach. If traditional approach does not } \\
\text { solve my problems, then I will look for solutions using } \\
\text { technology.” [\#15] }\end{array}$ \\
\hline & $\begin{array}{l}\text { The interviewee } \\
\text { prefers to use } \\
\text { technology } \\
\text { selectively in } \\
\text { teaching } \\
\text { (mentioned by } 11 \\
\text { interviewees) }\end{array}$ & (i) & $\begin{array}{l}\text { "I don't think all topics (in mathematics) can and should be } \\
\text { taught using technology. Rather than insisting the use of } \\
\text { technology, I would prefer considering first the right } \\
\text { pedagogy and then deciding whether to introduce } \\
\text { technology or not to it.” [\#07] } \\
\text { "I don't think we should use technology in every aspect. } \\
\text { For example, sometimes writing on the blackboard is faster } \\
\text { than typing on the computer, but it will be more convenient } \\
\text { for demonstration if we prepare it on the presentation slides } \\
\text { before the lesson. (So) it all depends on the specific needs } \\
\text { of the subject.” [\#11] }\end{array}$ \\
\hline & $\begin{array}{l}\text { Perceived ease of } \\
\text { use affects } \\
\text { perceived } \\
\text { usefulness } \\
\text { (mentioned by } 3 \\
\text { interviewees) }\end{array}$ & $\begin{array}{l}\text { (k) } \\
\text { (l) }\end{array}$ & $\begin{array}{l}\text { "If I cannot handle (the use of technology), an (seemingly) } \\
\text { effective approach is ineffective for me.” [\#01] } \\
\text { "If a tool is very powerful but too difficult to use, then it is } \\
\text { still not useful.” [\#09] }\end{array}$ \\
\hline $\begin{array}{l}\text { Computer } \\
\text { self-efficacy }\end{array}$ & $\begin{array}{l}\text { Computer self- } \\
\text { efficacy has effects } \\
\text { on intention of use } \\
\text { (mentioned by } 3 \\
\text { interviewees) }\end{array}$ & $\begin{array}{l}\text { (m) } \\
\text { (n) }\end{array}$ & $\begin{array}{l}\text { "Until I am familiar enough with the technology for } \\
\text { teaching students, and the students can understand my } \\
\text { teaching in this way, then I will use this new technology." } \\
\text { [\#01] } \\
\text { "I worry about running into (technical) problems during } \\
\text { lessons (and I cannot solve it), and then I need to change it } \\
\text { back into other methods (or even the traditional approach). I } \\
\text { may therefore need to prepare a backup plan for each } \\
\text { lesson." [\#19] }\end{array}$ \\
\hline $\begin{array}{l}\text { Subjective } \\
\text { norm }\end{array}$ & $\begin{array}{l}\text { It is the trend / } \\
\text { school's } \\
\text { expectations for } \\
\text { teachers to use } \\
\text { technology in } \\
\text { teaching } \\
\text { (mentioned by } 5 \\
\text { interviewees) }\end{array}$ & (o) & $\begin{array}{l}\text { "In-service teachers should accept and adopt the teaching } \\
\text { and learning with technology gradually according to the } \\
\text { change of era. Many schools have already been using } \\
\text { electronic whiteboard and upgrading their digital facilities. } \\
\text { Teachers should follow the trend if they intend to help the } \\
\text { education sector advance continuously or if they want to } \\
\text { survive in the field themselves." [\#05] }\end{array}$ \\
\hline & $\begin{array}{l}\text { Students expect } \\
\text { teachers to use } \\
\text { technology in } \\
\text { teaching } \\
\text { (mentioned by } 2 \\
\text { interviewees) }\end{array}$ & $\begin{array}{l}\text { (p) } \\
\text { (q) }\end{array}$ & $\begin{array}{l}\text { "Students are used to using the computers in this era of } \\
\text { technological advancements. They can feel bored if (the } \\
\text { teachers) only use the paper-based textbooks." [\#09] } \\
\text { "Even primary students are used to digital technologies } \\
\text { nowadays, and resists to the teachers when they are not } \\
\text { using them well.” [\#19] }\end{array}$ \\
\hline $\begin{array}{l}\text { Facilitating } \\
\text { conditions }\end{array}$ & $\begin{array}{l}\text { Time is important } \\
\text { (mentioned by } 3 \\
\text { interviewees) }\end{array}$ & (r) & $\begin{array}{l}\text { "I think only pre-service teachers will have the time during } \\
\text { practicums to analyse in details how to use technology in } \\
\text { each single lesson. This is a very realistic consideration." } \\
\text { [\#07] } \\
\text { "I currently find it easy to handle (educational technologies) } \\
\text { mainly because I have plenty of time now. I can spend one } \\
\text { day or two to study how to use a new technology. But, in } \\
\text { the future (when I become an in-service teacher), I may } \\
\text { have to spend time preparing for teaching with technology }\end{array}$ \\
\hline
\end{tabular}




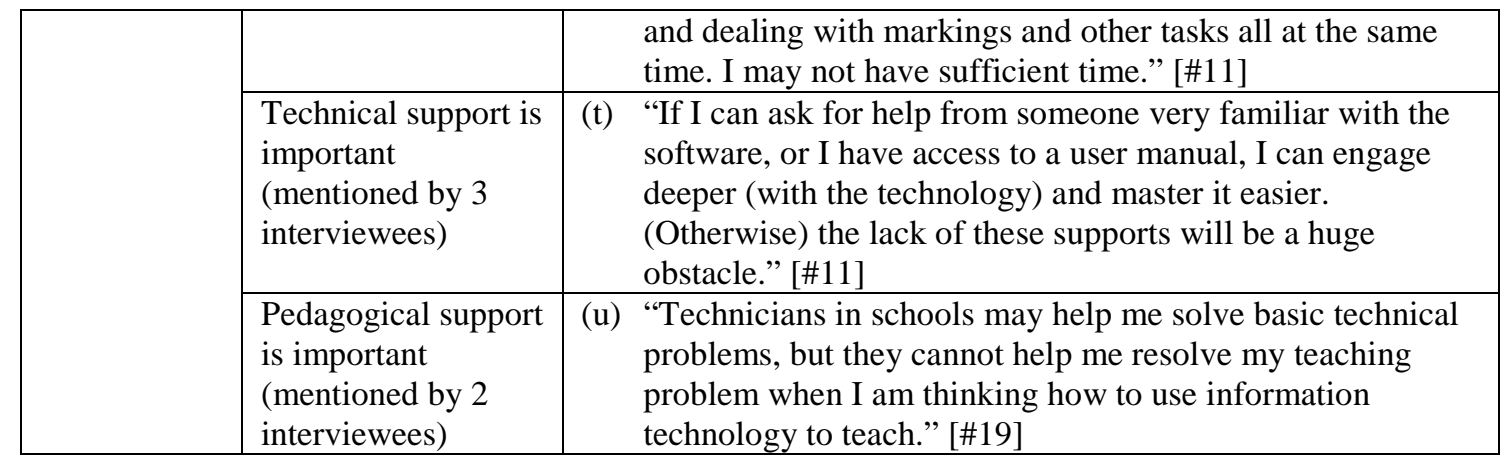

\section{Perceived usefulness}

One of the salient themes that stand out of the qualitative data is the emphasis on the usefulness of the technology. A total of 11 out of 14 interviewees expressed that the usefulness of the technology was an important consideration for them to use it in their own teaching, as exemplified in responses (a) to (d). In particular, in responses (c) and (d) the interviewees suggested that he/she would use the technology if it were useful, even if it was difficult to use. This shows a priority on usefulness over ease of use for some of the interviewees.

On the other hand, two responses show that this usefulness is evaluated not merely in terms of the functionality of the technology, but how well the technology helps them achieve their goal. At least some interviewees define this goal as an enhancement of their teaching effectiveness illustrated in responses (e) and (f). Apparently, the interviewees were pragmatic about using technology at work. This consideration is also relatively true rather than absolutely right. As illustrated in responses (g) and (h), some interviewees compare the use of technology with the so-called traditional approach and switch between the two depending on how well the two approaches perform towards their goal in teaching. This thinking is seen in 9 out of the 14 interviewees. Some interviewees recognised this comparison and selectivity of different teaching approaches, where using technology in teaching may not necessarily outperform the traditional approach in every scenario. Therefore, they tend to use technology in a selective manner when they find it more helpful in some scenarios of their teaching, as shown in responses (i) and (j). A total of 11 out of the 14 interviewees expressed this selective use of technology in teaching.

The relation between perceived usefulness and perceived ease of use is also revealed by 3 interviewees as exemplified in responses $(\mathrm{k})$ and $(\mathrm{l})$, who emphasised that ease of use was a pre-requisite for a piece of technology to be useful because otherwise people could not use it appropriately. The interviewees seem to regard technology as a tool that can potentially help them with their career goal, therefore they use it wherever they find it really helpful, and discard it otherwise.

\section{Computer self-efficacy}

Another theme arising from the interview is that of the affections associated with the computer self-efficacy of the interviewees, mentioned by 3 of the interviewees. In response (m), the interviewee expressed that apart from the usefulness/effectiveness consideration, it was also important for him/her to be familiar with the technology. Another interviewee illustrated in response (n) that he/she worried about getting into technical problems during the lessons. This is a common concern expressed by a few interviewees and they all thought that they might not be able to solve the problems on the spot quickly enough without affecting the lessons. This suggests why there is a direct impact of computer self-efficacy on behavioural intention of use in the quantitative model. On the other hand, there is no indication from the interview that the interviewees' perception on the ease of use of technology is related to their computer self-efficacy.

\section{Subjective norm}

The interviewees also used subjective norm as a supporting reason to their use of technology. One interviewee (response [o]) suggested that as many local schools were already equipped with electronic whiteboard and other computer facilities, it is necessary for teachers to follow this trend in order to advance their teaching skills or simply to " in the teaching career. Similar thinking was mentioned by a total of 5 
interviewees. Two other interviewees (responses [p] and [q]) said that students would expect them to use technology in teaching because otherwise they might feel bored or discontent. Presumably the interviewees thought that their teaching performance would be associated with their use or ability to use technology to pursue their teaching goal (e.g., to teach effectively) because as many schools were providing this kind of support, the school administration and even the students were expecting the teachers to use these facilities. Therefore, this result is consistent with the quantitative findings that subjective norm has a direct effect on perceived usefulness, which according to above depends on how helpful the technology may help the interviewees achieve their teaching goals.

\section{Facilitating conditions}

There are three kinds of facilitating conditions concerned by the interviewees. The first one is time. As illustrated in response (r) and (s), although the interviewees were still pre-service teachers, some of them seemed to realise the heavy workload ahead. In order to use the technology in class, or to learn about the technology in the first place, they had to put in time and effort. Although some interviewees might find technology easy to use, it was only because they still had time to study it as pre-service teachers. The lack of time, which they consider an important resource controlled by the school administration, would be a realistic constraint that may hinder their future attempt to use technology in their teaching.

Another concern is technical support as exemplified in response (t), in which the interviewee mentioned that the lack of support by technical persons or user manuals would be a major barrier to their attempt to use technology. In response (u), on the other hand, the interviewee pointed out that technical support alone was not sufficient. The teacher also needs support to incorporate the technology into the pedagogy in order to use technology in teaching. While the technical support team may assist the teachers in the technological aspect, and the teachers may be familiar with content and pedagogical knowledge, the latter may not have the knowledge or time to incorporate these together into a coherent teaching plan. In short, the lack of facilitating conditions in time, technical, and pedagogical support essentially makes the task more difficult. In total, these sub-themes were mentioned by 3, 3, and 2 interviewees respectively. This suggests why facilitating conditions are found to have very strong effect on perceived ease of use in the quantitative model.

\section{Discussion}

\section{Perceived usefulness has stronger total effect than perceived ease of use on behavioural intention of use}

Our results show that perceived usefulness is not a direct factor for behavioural intention of use. Instead, perceived usefulness is a direct factor of attitude, and the connection is much stronger (0.731) than the other direct factor, the perceived ease of use (0.211). Attitude also has a moderate effect (0.529) on behavioural intention. The standardised total effect of perceived usefulness on behavioural intention is 0.466 as shown in Table 8. Among the constructs contributing to behavioural intention in our model, perceived usefulness has the second strongest total effect following attitude. In contrast, the total effect of perceived ease of use on behavioural intention (0.281) is weaker than that of the perceived usefulness, consistent with other studies cited that use a TAM-like model with pre-service teachers (e.g., Aypay et al., 2012; Teo, 2010; Teo, Lee, Chai, \& Wong, 2009; Teo et al., 2008; Teo \& Ursavas, 2012; Wong, Teo, \& Russo, 2012). As mentioned previously, these quantitative results are consistent with the qualitative results that perceived usefulness is an important factor on behavioural intention of use, that it is more important than perceived ease of use, and that it is in part affected by perceived ease of use. The qualitative results demonstrate pragmatism as a reason behind these relations.

It is particularly helpful to compare the total effects of these two factors on behavioural intention because they can easily inform the design of teaching education curricula. As perceived usefulness has a greater influence than perceived ease of use on behavioural intention, it would be more effective to make the technology appear useful rather than to make it look easier, if we want to encourage its use. This resonates with the study by Kennedy and Fox (2013) who reported that students discard a given technology if there is no direct personal benefit. On the other hand, one possible reason that students are less concerned about the perceived ease of use may be that they are not yet facing the real challenges of teaching, and have yet to experience the workplace environment. This assertion needs to be investigated in further studies. 
In fact, one of our courses on the use of educational technology in mathematics aims to provide an opportunity for students to investigate the implications of using technology for teaching and learning in the mathematics curriculum. It is however not necessary for the students to agree with the usefulness of technology in order to fulfil the course learning outcomes. To encourage the students to use it in their future teaching practice, it is important that he/she demonstrates the usefulness to the students by using technology effectively in his/her own class, or by engaging the students in learning activities that show the power of effective integration of technology with innovative pedagogy. Since perceived ease of use is less influential than perceived usefulness, it may not be wise to attract students by teaching them to use technology that is easy to learn but not that useful.

On the other hand, it is intuitively true that the influence of perceived ease of use on attitude is exerted through perceived usefulness rather than on attitude directly. One criterion to determine the usefulness of technology is to consider how it could save time and effort. If pre-service teachers find a specific technology difficult to use, no matter how potentially useful it is, they would logically think that using it would increase their burden at work, or, in an extreme case, bring undesirable effects to their teaching unless they can master it during their lesson preparation. They would otherwise consider the technology not useful to them. The reverse is also true. If a given technology is perceived as useful and easy to use, teachers may then realise the usefulness of the technology more easily, thus leading to higher perceived usefulness.

\section{Computer self-efficacy has moderate impact on behavioural intention but no direct impact on perceived ease of use}

Based on our results, computer self-efficacy has a moderate role on behavioural intention with a total effect of 0.422. According to Yi and Hwang (2003), it confirms that application-specific self-efficacy could have effect on system use. Our qualitative results also suggest that some of our interviewees do not think he/she can handle the possible challenges arising when they use technology in teaching - an indication that computer self-efficacy can impact behavioural intention of use. Although qualitative data by their nature cannot be easily generalised, they suggest a possible reason behind the corresponding quantitative link between computer self-efficacy and behavioural intention.

On the other hand, the direct link of computer self-efficacy on perceived ease of use is not statistically supported in our data. Although this finding differs from the work by Davis, Bagozzi, and Warshaw (1989) which claims that perceived ease of use is anchored to general computer self-efficacy (Legris et al., 2003), our result is similar to what has been found by Chau (2001) in the Hong Kong context indicating that computer self-efficacy has no significant effect on perceived ease of use. According to Chau, the difference is due to the change of the targeted system. Indeed, empirical research studies have shown that perceived ease of use depends on multiple factors, which may or may not include computer self-efficacy (Agarwal \& Karahanna, 2000; Yi \& Hwang, 2003). Thus, as discussed by Compeau and Higgins (1995) and Chau (2001), the link between computer self-efficacy and perceived ease of use is currently not very conclusive in empirical literature.

Indeed, our distinctive result can be explained by the work of Venkatesh (2000). The research finding did point out that computer self-efficacy can be a determinant of perceived ease of use of system (or technology) after gaining a significant direct experience with the technology for a period of time consecutively. Specifically, users are expected to have various outcomes in the perceived ease of use of the systems from an objective standpoint (e.g., teaching primary mathematics), even they possess high/low computer self-efficacy with increasing direct experience with the target system (Venkatesh, 2000). In other words, the key factor that boosts the effect of self-efficacy toward perceived ease of use can depend on the user actual behavioural experience in a particular object rather than purely possessing a certain level of self-efficacy, and in our case it is the teaching experience with technology. Thus, our result shows that there is no direct effect between these two constructs as our students may only have a general experience in using technology rather than on teaching specifically. 


\section{Subjective norm has direct effect on perceived usefulness but not on perceived ease of use}

Subjective norm is found to have a direct effect on perceived usefulness, which aligns with some existing findings (Schepers \& Wetzels, 2007; Shen, Laffey, Lin, \& Huang, 2006), while Teo (2009) finds that subjective norm has direct effect on behavioural intention. The strength (0.313) is comparable to the other two direct factors, which are computer self-efficacy (0.322) and perceived ease of use (0.364). As shown by our qualitative results, these pre-service teachers perceive that educational technology is useful in achieving their teaching goal because its use constitutes part of their teaching performance. In addition, it is quite reasonable to observe that simply everyone wants the teachers to use educational technology does not imply ease of use. It aligns with the study on pre-service teachers in Singapore by Teo et al. (2009), where subjective norm has no direct impact on perceived ease of use.

According to Cheung, Chiu, and Lee (2011), this social phenomenon can be explained by the social influence theory (Kelman, 1958), the uses and gratification paradigm (Katz, 1959), and social presence theory (Short, Williams, \& Christie, 1976). Certainly, these pre-service teachers may or may not be aware of such sociocultural perspectives (Sanderson, 2010) toward the influence of technology acceptance. Our result simply shows that these pre-service teachers can develop a behavioural intention to adopt educational technology in teaching when their peers expect them to develop a similar intention to adopt it in classroom settings. The authors of this paper have also observed these social norms when teaching students in Hong Kong, which is common among Chinese learners For example, students here are usually passive and nonparticipative in classroom activities unless they have seen other peers do so, which is considered as studentinitiated collaborative learning strategies (Flowerdew, 1998) and group solidarity (Kennedy, 2002). They will quickly follow the norms to proceed and complete activities. This observation can be applied to their adoption of pedagogical design and educational technology in teaching.

Nevertheless, the total effect of subjective norm on behavioural intention is not as strong as others (0.160). This means the total effect on behavioural intention is overridden by other factors regardless of this social influence. In particular, both our qualitative and quantitative data have shown above the importance of perceived usefulness. Pre-service teachers who find the technology useful may still choose to experiment with it to some point even though others may be not be very supportive. Conversely, if they find the technology not useful, they may avoid using it as far as they could despite social pressure.

\section{Facilitating conditions have a strong effect on perceived ease of use}

Another phenomenon to note is that although facilitating conditions have a weak influence on behavioural intention, their direct influence on perceived ease of use is relatively strong at 0.739 . Facilitating conditions occur when teachers have resources to help, such as their own concrete knowledge, hardware and software in place, or a designated group of people to provide technical support to them (Teo, 2009). Our qualitative data suggest the availability of time to learn or set up the technology as another important resource considered by the pre-service teachers. If schools lack such resources, it may be difficult for teachers to sustain their perceived ease of use on a long term basis in the workplace since these resources are very important factors to influence the adoption to teaching (Groves \& Zemel, 2000). In our result, pre-service teachers seem to depend heavily on external resources when they consider whether educational technology is easy to use or not. Note that some existing works even consider that facilitating conditions can have a direct impact on the behavioural intention (Groves \& Zemel, 2000; Taylor \& Todd, 1995; Venkatesh \& Davis, 2000). In addition, Teo (2009) even found that facilitating condition has small to moderate effects to the perceived ease of use. No doubt, it is crucial for the pre-service teachers to feel comfortable to interact with technology in their teaching. According to Venkatesh (2000), it is suggested that the relationship between facilitating condition (or external control) and perceived ease of use is considered a long term effect when users judge the ease of use of technology. This notion may be applicable to the pre-service primary mathematics teachers in Hong Kong yet to be found in further study.

Of course it is always very difficult to use any educational technology for teaching if the workplace does not have the necessary facilities. In general, facilitating conditions should have a positive effect on the behavioural intention to use technology (Ngai, Poon, \& Chan, 2007). Without these in place, it would be expected that learning becomes more challenging because teachers have no way to implement technology into the classroom and become skilful in using it for their teaching. For instance, some primary schools in 
Hong Kong are advanced in their computer and network infrastructure with well-established technical support services. Students are even provided with tablet computers to bring to school for learning purposes. In this scenario, it is not surprising that teachers will find it easy to use technology for their teaching with great technical support (Williams, 2002). In contrast, teachers will find it quite difficult to teach with technology when performing a simple task takes a long time, such as switching on an older computer or out-dated projector. Teaching in a poor technology environment creates an unfavourable impression on students, who may feel that the teacher is not proficient in the use of technology. This definitely affects their behavioural intention indirectly through other constructs.

\section{Conclusions and Future Research}

Our study shows that our pre-service teachers generally have a positive attitude towards the use of educational technology, and they have a favourable perception of its usefulness for teaching purposes. In particular, our quantitative data show that perceived usefulness is more influential than perceived ease of use on the pre-service teachers' behavioural intention to use the technology. This implies that if we are to encourage pre-service teachers to use technology in their future teaching practice, it is more important to demonstrate the usefulness of technology than to make these technologies look easier. Moreover, our preservice teachers depend heavily on external resources, especially facilities, when they consider whether or not the technology is easy to use. Computer self-efficacy and subjective norms also affect behavioural intention. They are not as strong as other factors, but should not be neglected.

Note that we are aware of some issues related to the use of the original instrument to the local situation, which may impose limitations on the understanding of the topic in the current context of Hong Kong education. For this reason, follow-up interviews have been conducted to triangulate the quantitative data and the qualitative studies confirm our interpretation of the quantitative analysis. Thus, this mixed method approach is more comprehensive and suitable for discerning reasons underlying technology acceptance, and exploring any other hidden factors that were absent from the model, such as the details of the acceptance level gained through analysing and organising into the supporting subthemes.

In terms of the demographic characteristics, the results are limited to the understanding of technology acceptance without attempting to distinguish the differences in this regard, such as gender or years of study in the programme, which may influence the technology acceptances of pre-service teachers in this context. However, one observation from the Table 10 shows that facilitating conditions are clearly illustrated by the interviewees who are Year 3 or 4 students and have completed their practicum experience, while other years of students tend to suggest the importance of perceived usefulness and other factors in technology acceptance in the absence of teaching experience in local schools. This potential implication is worthwhile to be explored further so as to understand how practicum experience changes the ways of pre-service teachers in viewing the technology in teaching and learning. Other implications such as gender may be significant to the results since most of our participants in the quantitative analysis are female. Yet, there is no strong evidence to indicate the gender significance from our results.

In conclusion, our investigation has identified the key factors for Hong Kong pre-service teachers' influencing their technology acceptance in the future teaching. Understanding the belief of our future teachers toward the use of technology in teaching is a key driver to successful technology adoption in schools (Sugar, Crawley, \& Fine, 2004). These findings are our first step to our future promotion of technology use by teachers, and they are essential to inform policy makers and curriculum designers in teacher education. As Teo (2009) suggests, pre-service teachers should be provided more exploration to teaching with technology so as to build up their positive attitude toward the usage. The institution should enhance the training facilities to allow easy access to technology and technical supports so that both instructors and pre-service teachers can gain better experience with technology. Also, teacher's education programme should consider offering more courses in ICT in primary education and demonstrate the usefulness of technology and its ease of use in teaching and learning.

Future studies could be conducted in several directions at this stage. One direction is to conduct a larger scale of technology acceptance studies on pre-service primary teachers in Hong Kong. Since our completed work is limited to pre-service teachers in primary mathematics education, it is valuable to consider preservice teachers in other core disciplines in Hong Kong such as Chinese language, English language and general studies. The comparative studies can inform the Hong Kong Education Bureau and higher 
institutions how to promote the culture of teaching and learning with technology. In addition, in-service teachers could be studied and compared with the pre-service teachers as an attempt to find out the cause of change when entering to primary education sector. This study could lead to more insights in understanding the different attitudes toward the use of technology between these two groups. Longitudinal studies could be undertaken to follow the changes of teachers over the course of their careers.

\section{Acknowledgement}

This project is supported by the Small Research Grant 2013/14 from the Department of Mathematics and Information Technology in the Hong Kong Institute of Education.

\section{References}

Agarwal, R., \& Karahanna, E. (2000). Time flies when you're having fun: Cognitive absorption and beliefs about information technology usage. MIS Quarterly, 24(4), 665-694. Retrieved from http://www.jstor.org/stable/3250951

Ajzen, I. (1991). The theory of planned behavior. Organizational Behavior and Human Decision Processes, 50, 179-211. doi:10.1016/0749-5978(91)90020-T

Ajzen, I., \& Fishbein, M. (1977). Attitude-behavior relations: A theoretical analysis and review of empirical research. Psychological Bulletin, 84(5), 888-918.

Aypay, A., Celik, H. C., Aypay, A., \& Sever, M. (2012). Technology accpetance in education: A study of pre-service teachers in Turkey. Turkish Online Journal of Educational Technology, 11(4), 264-272. Retrieved from http://eric.ed.gov/?id=EJ989276

Barrett, P. (2007). Structural equation modelling: Adjudging model fit. Personality and Individual Differences, 42(5), 815-824.

Boomsma, A. (1983). On the robustness of LISREL (maximum likelihood estimation) against small sample size and non-normality (Doctoral dissertation). University of Groningen, Netherlands. Retrieved from http://www.rug.nl/research/portal/publications/pub(13671dbd-9743-4780-be47d8bb51909b28).html

Chau, P. Y. (2001). Influence of computer attitude and self-efficacy on IT usage behavior. Journal of End User Computing, 13(1), 26-33. doi:org/10.4018/joeuc.2001010103

Cheung, C. M. K., Chiu, P. Y., \& Lee, M. K. O. (2011). Online social networks: Why do students use facebook? Computers in Human Behavior, 27(4), 1337-1343. doi:org/10.1016/j.chb.2010.07.028

Cohen, L., Manion, L., \& Morrison, K. (2011). Research methods in education. Abingdon: Routledge.

Compeau, D. R., \& Higgins, C. A. (1995). Computer self-efficacy: Development of a measure and initial test. MIS Quarterly, 19(2), 189-211. doi:org/10.2307/249688

Creswell, J. W. (2002). Educational research: Planning, conducting, and evaluating quantitative. Upper Saddle River, NJ: Prentice Hall.

Davis, F. D. (1986). A technology acceptance model for empirically testing new end-user information systems: Theory and results (Doctoral dissertation). Massachusetts Institute of Technology, Massachusetts, MA. Retrieved from http://hdl.handle.net/1721.1/15192

Davis, F. D., Bagozzi, R. P., \& Warshaw, P. R. (1989). User acceptance of computer technology: A comparison of two theoretical models. Management Science, 35(8), 982-1002. doi:org/10.1287/mnsc.35.8.982

Dutton, W., Cheong, P., \& Park, N. (2004). The social shaping of a virtual learning environment: The case of a university-wide course management system. Electronic Journal of E-Learning, 2(1), 69-80. Retrieved from http://www.inf.ufes.br/ cvnascimento/artigos/issue1-art3-dutton-cheong-park.pdf

Fadel, C., \& Lemke, C. (2006). Technology in schools: What the research says. Retrieved from www.cisco.com/web/strategy/docs/education/TechnologyinSchoolsReport.pdf

Flowerdew, L. (1998). A cultural perspective on group work. English Language Teaching Journal, 52(4), 323-329. doi:org/10.1093/elt/52.4.323

Göğüş, A., Nistor, N., \& Lerche, T. (2012). Educational technology acceptance across cultures: A validation of the unified theory of acceptance and use of technology in the context of Turkish national culture. Turkish Online Journal of Educational Technology, 11(4), 394-408. Retrieved from http://eric.ed.gov/?id=EJ989305

Groves, M. M., \& Zemel, P. C. (2000). Instructional technology adoption in higher education: An action research case study. International Journal of Instructional Media, 27(1), 57-65. Retrieved from http://search.proquest.com/docview/204274119?pq-origsite=gscholar 
Hair, J. F., Black, W. C., Babin, B. J., Anderson, R. E., \& Tatham, R. L. (2006). Multivariate data analysis (Vol. 6). Upper Saddle River, NJ: Pearson Prentice Hall.

Hayes, E., \& Ohrnberger, M. (2013). The gamer generation teaches school : The gaming practices and attitudes towards technology of pre-service teachers. Journal of Technology and Teacher Education, 21(2), 153-177. Retrieved from http://www.editlib.org/p/41242/

Hu, L., \& Bentler, P. M. (1999). Cutoff criteria for fit indexes in covariance structure analysis: Conventional criteria versus new alternatives. Structural Equation Modeling: A Multidisciplinary Journal, 6(1), 1-55. doi:org/10.1080/10705519909540118

Irvine, V., \& Birch, A. (2009). Preservice teachers' acceptance of ICT integration in the classroom: Applying the UTAUT model. Educational Media International, 46(4), 295-315. doi:org/10.1080/09523980903387506

Katz, E. (1959). Mass communication research and the study of popular culture: An editorial note on a possible future for this journal. Studies in Public Communication, 2, 1-6. Retrieved from http://repository.upenn.edu/asc_papers/165

Kelman, H. C. (1958). Compliance, identification, and internalization three processes of attitude change. Journal of Conflict Resolution, 2(1), 51-60. doi:org/10.1177/002200275800200106

Kennedy, D. M., \& Fox, B. (2013). “Digital natives”: An Asian perspective for using learning technologies. International Journal of Education and Development Using Information and Communication Technology, 9(1), 64-79. Retrieved from http://search.proquest.com/docview/1353086742?pq-origsite=gscholar

Kennedy, P. (2002). Learning cultures and learning styles: Myth-understandings about adult (Hong Kong) Chinese learners. International Journal of Lifelong Education, 21(5), 430-445. doi:org/10.1080/02601370210156745

Kiraz, E., \& Ozdemir, D. (2006). The relationship between educational ideologies and technology acceptance in pre-service teachers. Educational Technology \& Society, 9(2), 152-165. Retrieved from http://www.jstor.org/stable/jeductechsoci.9.2.152

Kirmizi, Ö. (2014). Measuring technology acceptance level of Turkish pre-service English teachers by using technology acceptance model. Educational Research and Reviews, 9(23), 1323-1333. doi:org/10.5897/ERR2014.1970

Klem, L. (2000). Structural equation modeling. In L. Grimm, \& P. Yarnold (Eds.), Reading and understanding multivariate statistics (volume II). Washington, WA: American Psychological Association.

Kline, R. B. (2005). Principles and practice of structural equation modeling (2nd ed.). New York, NY: Guilford.

Lee, Y.-H., Hsieh, Y.-C., \& Chen, Y.-H. (2013). An investigation of employees' use of e-learning systems: Applying the technology acceptance model. Behaviour \& Information Technology, 32(2), 173-189. doi:org/10.1080/0144929X.2011.577190

Legris, P., Ingham, J., \& Collerette, P. (2003). Why do people use information technology? A critical review of the technology acceptance model. Information \& Management, 40(3), 191-204. doi:org/10.1016/S0378-7206(01)00143-4

Lei, P. W., \& Wu, Q. (2007). Introduction to structural equation modeling: Issues and practical considerations. Educational Measurement: Issues and Practice, 26(3), 33-43. doi:org/10.1111/j.17453992.2007.00099.x

Ma, W. W. K., Andersson, R., \& Streith, K.-O. (2005). Examining user acceptance of computer technology : An empirical study of student teachers. Journal of Computer Assisted Learning, 21(6), 387-395. doi:org/10.1111/j.1365-2729.2005.00145.x

Mac Callum, K., \& Jeffrey, L. (2014). Comparing the role of ICT literacy and anxiety in the adoption of mobile learning. Computers in Human Behavior, 39, 8-19. doi:org/10.1016/j.chb.2014.05.024

Marques, B. P., Villate, J. E., \& Carvalho, C. V. (2011). Applying the UTAUT model in engineering higher education: Teacher's technology adoption. Proceedings of Information Systems and Technologies (CISTI), 2011 6th Iberian Conference, Chaves, 1-6. Retrieved from http://ieeexplore.ieee.org/xpl/freeabs_all.jsp?arnumber=5974236\&abstractAccess=no\&userType=inst

Mishra, P., \& Koehler, M. J. (2006). Technological pedagogical content knowledge: A framework for teacher knowledge. Teachers College Record, 108(6), 1017-1054. doi:org/10.1111/j.14679620.2006.00684.x

Ngai, E. W. T., Poon, J. K. L., \& Chan, Y. H. C. (2007). Empirical examination of the adoption of WebCT using TAM. Computers \& Education, 48(2), 250-267.

doi:org/10.1016/j.compedu.2004.11.007 
Nistor, N., Lerche, T., Weinberger, A., Ceobanu, C., \& Heymann, O. (2014). Towards the integration of culture into the unified theory of acceptance and use of technology. British Journal of Educational Technology, 45(1), 36-55. doi:org/10.1111/j.1467-8535.2012.01383.x

Prensky, M. (2001). Digital natives, digital immigrants. On the Horizon, 9(5), 1-6. Retrieved from http://www.nnstoy.org/download/technology/Digital\%20Natives\%20-\%20Digital\%20Immigrants.pdf

Renaud, K., \& Van Biljon, J. (2008). Predicting technology acceptance and adoption by the elderly: A qualitative study. Proceedings of the 2008 annual research conference of the South African Institute of Computer Scientists and Information Technologists on IT research in developing countries: Riding the wave of technology, Garden Route, Wilderness, South Africa, 210-219. doi:org/10.1145/1456659.1456684

Roschelle, J. M., Pea, R. D., Hoadley, C. M., Gordon, D. N., \& Means, B. M. (2001). Changing how and what children learn in school with computer-based technologies. Children and Computer Technology, 10 (2), 76-101. doi:org/10.2307/1602690

Sanderson, C. (2010). Social psychology. Hoboken, NJ: Wiley.

Schacter, J. (1999). The impact of education technology: What the most current research has to say. Retrieved from http://eric.ed.gov/?id=ED430537

Schepers, J., \& Wetzels, M. (2007). A meta-analysis of the technology acceptance model: Investigating subjective norm and moderation effects. Information \& Management, 44(1), 90-103. doi:org/10.1016/j.im.2006.10.007

Shen, D., Laffey, J., Lin, Y., \& Huang, X. (2006). Social influence for perceived usefulness and ease-ofuse of course delivery systems. Journal of Interactive Online Learning, 5(3), 270-282. Retrieved from http://www.ncolr.org/jiol/issues/pdf/5.3.4.pdf

Short, J., Williams, E., \& Christie, B. (1976). The social psychology of telecommunications. London: John Wiley \& Sons.

Sieche, S., Krey, B., \& Bastiaens, T. (2013). Investigating students' usage and acceptance of electronic books. Journal of Educational Multimedia and Hypermedia, 22(4), 465-487. Retrieved from http://www.editlib.org/p/43705/

Steiger, J. H. (2007). Understanding the limitations of global fit assessment in structural equation modeling. Personality and Individual Differences, 42(5), 893-898. doi:org/10.1016/j.paid.2006.09.017

Straub, D., Keil, M., \& Brenner, W. (1997). Testing the technology acceptance model across cultures: A three country study. Information \& management, 33(1), 1-11. doi:org/10.1016/S0378-7206(97)000268

Straub, E. T. (2009). Understanding technology adoption: Theory and future directions for informal learning. Review of Educational Research, 79(2), 625-649. doi:org/10.3102/0034654308325896

Sugar, W., Crawley, F., \& Fine, B. (2004). Examining teachers' decisions to adopt new technology. Educational Technology and Society, 7(4), 201-213. Retrieved from http://www.jstor.org/stable/jeductechsoci.7.4.201

Tabachnick, B. G., \& Fidell, L. S. (2012). Using multivariate statistics (6th ed.). Boston, MA: Pearson.

Taylor, S., \& Todd, P. A. (1995). Understanding information technology usage: A test of competing models. Information Systems Research, 6(2), 144-176. doi:org/10.1287/isre.6.2.144

Teo, T. (2009). Modelling technology acceptance in education: A study of pre-service teachers. Computers \& Education, 52(2), 302-312. doi:org/10.1016/j.compedu.2008.08.006

Teo, T. (2010). A path analysis of pre-service teachers' attitudes to computer use: Applying and extending the technology acceptance model in an educational context. Interactive Learning Environments, 18(1), 65-79. doi:org/10.1080/10494820802231327

Teo, T., Lee, C. B., Chai, C. S., \& Wong, S. L. (2009). Assessing the intention to use technology among pre-service teachers in Singapore and Malaysia: A multigroup invariance analysis of the technology acceptance model (TAM). Computers \& Education, 53(3), 1000-1009. doi;org/10.1016/j.compedu.2009.05.017

Teo, T., Luan, W. S., \& Sing, C. C. (2008). A cross-cultural examination of the intention to use technology between Singaporean and Malaysian pre-service teachers: An application of the technology acceptance model (TAM). Educational Technology \& Society, 11(4), 265-280. Retrieved from http://www.jstor.org/stable/jeductechsoci.11.4.265

Teo, T., \& Ursavas, Ö. F. (2012). Technology acceptance of pre-service teachers in Turkey: A crosscultural model validation study. International Journal of Instructional Media, 39(3), 193-201. Retrieved from http://0- 
search.ebscohost.com.edlis.ied.edu.hk/login.aspx?direct=true \&db=eft\&AN=78855030\&site=ehostlive\&scope $=$ site

Venkatesh, V. (2000). Determinants of perceived ease of use: Integrating control, intrinsic motivation, and emotion into the technology acceptance model. Information systems research, 11(4), 342-365. doi:org/10.1287/isre.11.4.342.11872

Venkatesh, V., \& Davis, F. D. (2000). A theoretical extension of the technology acceptance model: Four longitudinal field studies. Management Science, 46(2), 186-204. doi:org/10.1287/mnsc.46.2.186.11926

Venkatesh, V., Morris, M. G., Davis, G. B., \& Davis, F. D. (2003). User acceptance of information technology: Toward a unified view. MIS Quarterly, 27(3), 425-478. Retrieved from http://www.jstor.org/stable/30036540

Wenglinsky, H. (1998). Does it compute? The relationship between educational technology and student achievement in mathematics. Princeton, NJ: Policy Information Center, Educational Testing Service.

West, R. E., Waddoups, G., \& Graham, C. R. (2006). Understanding the experiences of instructors as they adopt a course management system. Educational Technology Research and Development, 55(1), 1-26. doi:org/10.1007/s11423-006-9018-1

Williams, P. (2002). The learning web: The development, implementation and evaluation of internetbased undergraduate materials for the teaching of key skills. Active Learning in Higher Education, 3(1), 40-53. doi:org/10.1177/1469787402003001004

Wong, K. T., Teo, T., \& Russo, S. (2012). Influence of gender and computer teaching efficacy on computer acceptance among Malaysian student teachers: An extended technology acceptance model. Australasian Journal of Educational Technology, 28(7), 1190-1207. Retrieved from http://ajet.org.au/index.php/AJET/article/view/796

Yi, M. Y., \& Hwang, Y. (2003). Predicting the use of web-based information systems: Self-efficacy, enjoyment, learning goal orientation, and the technology acceptance model. International Journal of Human Computer Studies, 59(4), 431-449. doi:org/10.1016/S1071-5819(03)00114-9

Yuen, A. H. K., \& Ma, W. W. K. (2002). Gender differences in teacher computer acceptance. Journal of Technology and Teacher Education, 10(3), 365-382. Retrieved from http://www.editlib.org/p/15142/

Corresponding author: Gary K. W. Wong, wongkawai@ied.edu.hk

Australasian Journal of Educational Technology (C) 2015.

Please cite as: Wong, G.K.W. (2015).Understanding technology acceptance in pre-service teachers of primary mathematics in Hong Kong. Australasian Journal of Educational Technology, 31(6), 713-735. 